thư hạ họng thanh quản giai đoạn III, IV bằng phác đồ hóa xạ trị đồng thời với cisplatin năm $2011(56,7 \%))^{3,8}$

\section{Tác dụng phụ}

- Độc tính trên huyết học, gan, thận. Trong quá trình điều trị đến khi kết thúc hóa xạ trị đồng thời, có 1 trường hợp bị ảnh hưởng bởi quá trình hóa xạ trị làm men gan ALT tăng độ 3 và 1 trương hợp AST tăng độ 3 . Trên hệ huyết học, có 8 trường hợp bạch cầu hạ độ 2 chiếm $25,8 \% .6,4 \%$ huyết sắc tố hạ độ 2 và $6,4 \%$ tiểu câu ha độ 1 .

\section{- Tác dụng phụ của xạ trị}

Viêm miệng do tia xạ. Kết quả trong nghiên cứu của chúng tôi, tỷ lệ bệnh nhân bị viêm miệng trong quá trình điểu trị là $100 \%$, trong đó có $9,6 \%$ gặp ở độ $1,45,2 \%$ độ 2 và $45,2 \%$ bị viêm miệng độ 3 . Tî lệ viêm viêm miệng độ 3 ở nghiên cứu này cao hơn so với nghiên cứu của Vũ Việt Anh (14,3\% độ 3, 71,4\% độ $2,14,3 \%$ độ 1). ${ }^{9}$

Tác dụng phụ trên da. Trong nghiên cứu của chúng tôi, các tổn thương da do tia xa gặp tỷ lệ 38,7\% bệnh nhân bị độc tính trên da cấp độ 2 . Kết quả này thấp hơn so với nghiên cứu của Vũ Việt Anh là $66,7 \% .{ }^{9}$

\section{KẾT LUẬN}

Đối với bệnh nhân UT Thanh quản giai đoạn III - IV có chỉ định phẫu thuật mà từ chối mổ hoặc có bệnh nội khoa chống chỉ định mổ được điều trị hóa xạ trị đồng thời (IMRT) cho tỷ lệ đáp ứng toàn bộ sau hóa xạ trị là $87 \%$, tỷ lệ đáp ứng 1 phần là $13 \%$, không có bệnh nhân nào không đổi sau điều trị. Các độc tính ở mức chấp nhận được trên hệ huyết học là hạ bạch câu độ II
(25,8\%), hạ tiểu cầu độ II $(19,4 \%)$, viêm da độ II do xạ trị $(38,7 \%)$, viểm miệng độ III do xạ trị $(45,2 \%)$

\section{TÀI LIÊUU THAM KHẢO}

1. Freddie B., Jacques F., Isabelle S., Rebecca L.S., Lindsey A.T., Ahmedin J. Global cancer statistics 2018: GLOBOCAN estimates of incidence and mortality worldwide for 36 cancers in 185 countries. CA Cancer J Clin. 2018;68(6):394-424.

2. C R Popescu., S V G Bertesteanu., D Mirea., Raluca G., Diana I., B Popescu. The epidemiology of hypopharynx and cervical esophagus cancer. J Med Life. 2010;3(4):396-401.

3. Đàm Trong Nghĩa. Nghiên cứu ứng dụng hóa trì trước phối hợp hóa xạ trị đồng thời ung thư hạ hong thanh quản giai đoan III, IV(MO): Luận án Tiến sĩ Y hoc, Trướng Đại hooc Y Hà Nội; 2018.

4. Phạm Tuẩn Cảnh, Nguyễn Hoàng Huy. Nghiên cứu đặc điểm lâm sàng ung thư thanh quản tại Bênh viện Tai Mũi Họng trung ương. $Y$ học thực hà̀nh. 2011;768(6):69-71.

5. Marshall R. P., Diane M.H., Cesar R.B., et al. Cisplatin and Fluorouracil Alone or with Docetaxel in Head and Neck Cancer. N Engl J Med. 2007;357(17):1705-1715.

6. Arlene A.F., Helmuth G., Moshe M., et al. Concurrent Chemotherapy and Radiotherapy for Organ Preservation in Advanced Laryngeal Cancer. N Engl J Med. 2003;27(349):22.

7. Thái Đình Hiếu, Nguyễn Tiến Quang. Nghiên cứu đặc điểm lâm sàng, cận lâm sàng ung thư ha hong - thanh quản giai đoạn IIIIIVA_B tại bênh viền Ung bướu Nghê An năm 2020. Tạp chí Y hộc Việt Nam. 2021;501(1):199-203.

8. Từng NT. Nghiên cứu một số đặc điểm lâm sàng, cận lâm sàng và kết quả hoá - xạ trị gia tốc đông thời ung thư ha họng -thanh quản giai đoạn III IVB không mổ được tại Bênh viện K 2011: Luận án Tiến sỹ Y học Trường Đại học Y Hà Nội; 2011.

9. Anh VV. Đánh giá kêt quả điêu trị bố trợ sau mổ ung thư lưỡi tại bệnh viện $K$ : Luận văn Thạc sĩ Y học, Trường đại học Y Hà Nội; 2015.

\title{
SỰ HÀI LÒNG VỀ DỊCH VỤ GIÁO DỤC CỦA SINH VIÊN HÊ BÁC SĨ NĂM THỨ 4 ĐẾN NĂM THỨ 6 TRƯỜ'NG ĐẠI HỌC Y HÀ NộI
}

\author{
Hoàng Việt Hưng ${ }^{1}$, Vũ Thu Hoài ${ }^{1}$, Phạm Tùng Sơn ${ }^{1}$,
} Nguyễn Thái Bình ${ }^{2}$, Vũ Minh Tuấn ${ }^{2}$

\section{TÓM TẮT.}

Mục tiêu: Nghiên cứu nhằm tìm hiểu sự hài lòng về dịch vụ giáo dục và phân tích một số yếu tố liên

\author{
${ }^{1}$ Trường Đại học Y Hà Nội \\ 2Viện Đào tạo YHDP \& YTCC, Trường Đại học Y Hà Nội \\ Chịu trách nhiệm chính: Vũ Minh Tuấn \\ Email: vuminhtuan@hmu.edu.vn \\ Ngày nhận bài: 17.8.2021 \\ Ngày phản biện khoa học: 11.10.2021 \\ Ngày duyệt bải: 22.10.2021
}

quan đến sự hài lòng của sinh viên hệ bác sĩ từ năm thứ 4 đến năm thứ 6 trường Đại học $Y$ Hà Nội. Phương pháp: Nghiên cứu mô tả cắt ngang, khảo sát trên 712 đối tượng theo bộ câu hỏi sẵn có của Bộ GD\&DT. Kết quả: $67,4 \%$ sinh viên đánh giá "Hài lòng" hoăc "Rất hài lòng" về chất lượng dịch vụ giáo dục Nhà trường. Phân tích mô hình hổi quy Logistic đa biến nhận thấy có mối liên quan giữa giới tính [OR = 1,4; CI: $1,02-1,93]$, dân tộc [OR = 2,27; CI: 1,04 $4,97]$, năm học [OR $=0,61 ; \mathrm{CI}: 0,42-0,89]$ và nơi ở hiện tại của sinh $[\mathrm{OR}=0,58 ; \mathrm{CI}: 0,36-0,95]$ với mức độ hài lìng chung về chất lượng dịch vụ giáo dục Nhà trường. 
Tư khóa: Sự hài lòng, dịch vụ giáo dục, sinh viên, Đại học Y Hà Nội

\section{SUMMARY \\ MEASURING 4TH TO 6TH YEAR MEDICAL STUDENTS' SATISFACTION WITH EDUCATIONAL SERVICES QUALLITY AND RELATIONSHIP WITH SERVICES QUALITY IN HANOI MEDICAL UNIVERSITY}

A cross - sectional study was implemented to analysis the satisfaction of educational services and some factors related to the satisfaction of 712 medical students from the 4th to the 6th year of Hanoi Medical University. Results show that $67,4 \%$ of students feel satisfied with the quality of educational services of the University. The multivariable logistic regression model led to results: Gender [OR $=1,4 ; \mathrm{CI}: 1,02-1,93$, ethnicity [OR $=2,27 ; \mathrm{CI}: 1,04-4,97]$, the grade [OR $=0,61 ;$ CI: $0,42-0,89] ;$ and current residence of students $[\mathrm{OR}=0,58 ; \mathrm{CI}: 0,36-0,95]$ were correlate with the satisfaction with educational services.

Keywords: Satisfaction, educational services, medical students, Hanoi Medical University

\section{I. ĐĂT VẤN ĐỀ}

Trong bối cảnh nền kinh tế thị trường phát triển mạnh, giáo dục đã dần trở thành một loại hình dịch vụ mà trong đó người học chính là khách hàng. Thị trường giáo dục dần phát triển khắp nơi, các trường đại học được thành lập với những mô hình đào tạo đa dạng. Từ đó nảy sinh tính canh tranh trong chất lượng dịch vụ đào tạo nhằm thu hút người học. Theo Parasuraman [1], "chất lượng dịch vụ" là khoảng cách giữa sự mong đợi của khách hàng về dịch vụ và sự cảm nhận thực tế khách hàng nhận được sau khi tiêu dùng sản phẩm. Theo đó, Bộ Giáo Dục \& Đào Tạo đã xây dựng đề án "Đo lường sự hài lòng của người dân đối với DVGD công giai đoạn 2016-2020", ban hành Kế hoạch chi tiết thực hiện hàng năm, kèm theo bộ công cụ khảo sát và tài liệu hướng dẫn triển khai [2],[3]. Nhiều trường đại học trong nước đã tiến hành nghiên cứu khảo sát. Tuy nhiên, các trường, khoa ngành Y tế, mặc dù đóng vai trò rất quan trọng, liên quan đến mọi ngành nghề khác nhau trong xã hội, chưa có nhiều đề tài triển khai về vấn đề này.
Trường Đại học $Y$ Hà Nội là một trong nhũng trường đại học trọng điểm quốc gia Việt Nam, trực thuộc Bộ $Y$ tế, là mắt xích quan trọng trong hệ thống $Y$ tế, đảm bảo nhân lực cho công tác chăm sóc và nâng cao sức khỏe nhân dân. Hệ thống đào tạo trường Đại học Y Hà Nội bao gồm 4 chuyên ngành hệ bác sĩ: ngành Bác sĩ Đa khoa, ngành Bác sĩ Y học Dự phòng, ngành Bác sĩ Răng Hàm Mặt, và ngành Bác sĩ Y học Cố truyền. Với nội dung đào tạo đa dạng, các sinh viên hệ bác sĩ từ năm thứ 4 đến năm thứ 6 đã trải nghiệm hầu như hoàn thiện các khía cạnh giáo dục của Nhà trường. Vì vậy, chúng tôi lựa chọn nghiên cứu "Sự hài lòng về dịch vụ giáo dục của sinh viên hể bác sĩ từ năm thứ 4 đến nằm thứ 6 trường Đại hoc $Y$ Hà Nôii" với muc tiêu: Mô tả sự hài lòng và phân tích một số yêu tố liên quan đến dịch vụ giáo dục.

II. ĐỐI TƯợNG VÀ PHƯƠNG PHÁP NGHIÊN CỨU

2.1. Đối tượng, địa điểm và thời gian nghiên cứu: Nghiên cứu được thực hiên trên sinh viên hệ bác sỹ đang theo học tại trường Đại học Y Hà Nội từ tháng 12/2020 đên tháng 05/2021.

Tiêu chuẩn lựa chọn: Sinh viên hệ bác sĩ năm thứ 4 đến năm thứ 6 đang theo học tại trường Đại học Y Hà Nội.

Tiêu chuẩn loại trừ: Sinh viên học hệ bác sỹ năm thứ nhất đển năm thứ 3 và sinh viên học hệ cử nhân y khoa.

2.2. Phương pháp nghiên cứu:

- Thiết kế nghiên cứu: Mô tả cắt ngang Cỡ mẫu và cách chọn mẫu:

+ Cỡ mẫu: ước lượng một tỉ lệ:

$\mathbf{n}=Z_{1-\alpha / 2}^{2} \frac{p(1-p)}{(p \varepsilon)^{2}}$

Với $p$ : Tỉ lệ sinh viên hài lòng với CLDVGD là 71.3\% [4] $\rightarrow$ Cõ̃ mẫu tối thiểu nghiên cứu cần có 630 sinh viên.

+ Cách chọn mẫu: ngẫu nhiên phân tầng, mỗi khối chọn 210 sinh viên. Thực tế thu được 712 phiếu.

- Đo lường sự hài lòng về dịch vụ giáo dục theo tiêu chí của Bộ giáo dục:

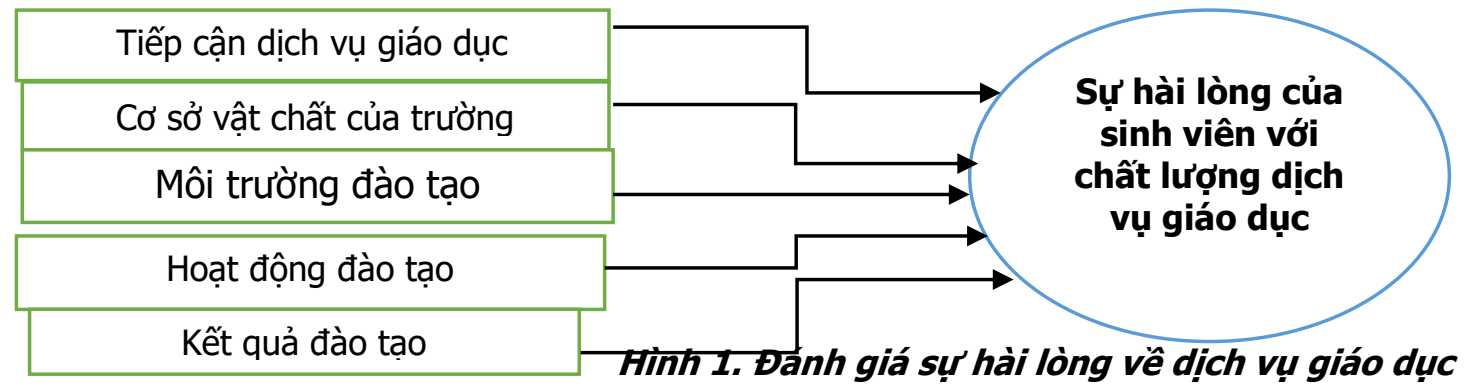


Trong đó:

- Tiếp cận DVGD: Thông tin mà người học tiếp cận được về DVGD như các thủ tục nhập học, học phí, các chính sách hỗ trợ sinh viên.

- Cơ sở vật chất của trường: Biểu hiện bên ngoài của cơ sở vật chất bao gồm phòng học, hệ thống công nghệ thông tin, thư viện, ký túc xá.

- Môi trường đào tạo: Bao gồm môi trường tâm lí, xã hội và cảnh quan.

- Hoạt động đào tạo: Mục tiêu đầo tạo; kế hoạch đào tạo; phướng pháp giảng dạy của giảng viên; kết quả kiểm tra, đánh giá; hoạt động hướng nghiệp.

- Kết quả đào tạo: Cảm nhận của người học về kiến thức, kỹ năng được học phục vụ cho công việc tương lai; cơ hội để rèn luyện nhân cách.

Công cụ và phương pháp thu thập số liệu
+ Công cụ: Bộ câu hỏi "Đo lường sự hài lòng của người dân đối với dịch vụ giáo dục công" của Bộ giáo dục năm 2017"[3].

+ Cách thu thập: gửi link khảo sát trực tuyến Google Doc.

\section{- Đánh giá điểm hài lòng được phân loại} như sau:

+ Từ 1 đến dưới 4 điểm: Không hài lòng; từ 4 đến 5 điểm: Hài lòng;

+ Điểm hài lòng của câu hỏi (ĐHLCH) là điểm trung bình của câu hỏi đó:

ĐHLCH $=$ ì Số lượt trả lời $x$ i/Tổng số đối tượng

Xử lý số liệu bằng các phương pháp thống kê y họ: tần suất, tỷ lệ \%, tỷ suất chênh OR$95 \% \mathrm{CI}$

\section{KẾT QUẢ NGHIÊN CỨU}

Bảng 1: Đặc điểm của đôii tượng nghiên cứu

\begin{tabular}{|c|c|c|c|c|c|}
\hline Đă̆c điếm & $\mathbf{n}$ & Tỷ lệ \% & Đặc điếm & $\mathbf{n}$ & Tỷ lệ \% \\
\hline Năm học & & & Nơi ở & & \\
\hline Năm thứ 4(Y4) & 276 & 38,8 & Ơ cùng gia đình & 122 & 17,2 \\
\hline Năm thứ 5 (Y5) & 223 & 31,3 & Ơ Ký túc xá & 169 & 23,7 \\
\hline Năm thứ 6 (Y6) & 213 & 29,9 & Ơ phòng trọ & 421 & 59,1 \\
\hline Giới tính & & & Dân tộc & & \\
\hline Nam & 283 & 39,7 & Kinh & 668 & 93,8 \\
\hline Nữ & 429 & 60,3 & Khác & 44 & 6,2 \\
\hline
\end{tabular}

Nhân xét: Tỷ lê sinh viên ba khối Y4, Y5, Y6 tham gia nghiên cứu chiếm lần lượt là: $38,8 \%$; $31,3 \% ; 29,9 \%$. Có tới $60,3 \%$ sinh viên tham gia khảo sát là nữ. Bên cạnh đó, sinh viên tham gia nghiên cứu chủ yếu ở phòng trọ ngoài $(59,1 \%)$. Sinh viên ở tại ký túc xá trường chiếm $23,7 \%$ và sinh viên ở cùng gia đình chiếm $17,2 \%$. Chủ yếu sinh viên là dân tộc Kinh $(93,8)$.

Bảng 2: Điếm và tý lệ hài lòng của sinh viên với dịch vụ giáo dục

\begin{tabular}{|c|c|c|}
\hline $\begin{array}{c}\text { Sự hài lòng của sinh } \\
\text { viến với dịch vụ giáo dục }\end{array}$ & $\begin{array}{c}\text { Điếm hài } \\
\text { lòng }\end{array}$ & $\begin{array}{c}\text { Tỷ lệ hài } \\
\text { lòng }\end{array}$ \\
\hline Tiếp cận dịch vụ giáo dục & $3,7 \pm 0,6$ & 66,0 \\
\hline Cơ sở vật chất của trường & $3,7 \pm 0,7$ & 63,6 \\
\hline Môi trường đào tạo & $3,8 \pm 0,7$ & 72,7 \\
\hline Hoạt động đào tạo & $3,7 \pm 0,7$ & 66,1 \\
\hline Kềt quả đào tạo & $3,5 \pm 0,7$ & 54,9 \\
\hline Hài lòng chung & $3,7 \pm 0,7$ & $67,4 \%$ \\
\hline
\end{tabular}

Nhận xét: - ĐHLC của sinh viên về yếu tố Tiếp cận dịch vụ giáo dục dao động từ 3,1 đến 4,3; TLHLC đạt 66,0\%;

- Về cơ sở vật chất của trường, ĐHLC dao động từ 3,0 đến 4,4; TLHLC đạt 63,6\%;

- Phản hồi của sinh viên về yếu tố Môi trường đào tạo có kết quả khả quan. với ĐHLC đạt từ 3,1 đển 4,5 và TLHLC đạt $72,7 \%$;
- ĐHLC của sinh viên về yễu tố Hoạt động đào tạo dao động từ 3,0 đến 4,$4 ;$ TLHLC đạt $66,1 \%$;

- Về kết quả đào tạo, ĐHLC dao động từ 2,8 đến 4,2 điểm; TLHLC đạt 54,9\%;

- Với câu hỏi "Mức độ hài lòng nói chung của anh/chị về dịch vụ giáo dục của trường như thễ nào", kết quả thu được ĐHLCH là $3,7 \pm 0,7$. Có 415 sinh viên chọn 4 điểm cho câu hỏi đánh giá chung, chiếm tỉ lệ lớn nhất (58,3\%); 7 sinh viên lựa chọn 1 điểm, chiếm tỉ lệ thấp nhất trong 5 lựa chọ $(1,0 \%)$. TLHLCH đat $67,4 \%$ tương đương với 480 sinh viên có lựa chọn 4 hoặc 5.

Bảng 3. Mối liên quan đêén hài lòng chung

\begin{tabular}{|c|c|c|c|}
\hline $\begin{array}{c}\text { Yếu } \\
\text { tố }\end{array}$ & $\begin{array}{c}\text { Hài } \\
\text { lòng } \\
\mathbf{( \% )}\end{array}$ & $\begin{array}{c}\text { Chưa hài } \\
\text { lòng } \\
\mathbf{( \% )}\end{array}$ & OR, $\mathbf{9 5 \%}$ CI \\
\hline \multicolumn{4}{|c|}{ Giới } \\
\hline Nam & 62,9 & 37,1 & 1 (nhóm tham chiếu) \\
\hline Nữ & 70,4 & 29,6 & $1,40(1,02-1,93)^{*}$ \\
\hline \multicolumn{4}{|c|}{ Dân tộc } \\
\hline Kinh & 66,5 & 33,5 & 1 (nhóm tham chiếu) \\
\hline Khác & 81,8 & 18,2 & $2,27(1,04-4,97)^{*}$ \\
\hline \multicolumn{4}{|c|}{ Năm học } \\
\hline Thứ 4 & 71,0 & 23,0 & 1 (nhóm tham chiếu) \\
\hline Thứ 5 & 67,0 & 30,0 & $0,95(0,65-1,40)$ \\
\hline
\end{tabular}




\begin{tabular}{|c|c|c|c|}
\hline Thứ 6 & 60,1 & 39,9 & $0,61(0,42-0,89)^{*}$ \\
\hline \multicolumn{3}{|c|}{ Nơi ơ hiện tại } \\
\hline $\begin{array}{c}\text { Ký túc xá } \\
\text { Đại học Y } \\
\text { Hà̀ Nội }\end{array}$ & 69,8 & 30,2 & $\begin{array}{c}1 \text { (nhóm } \\
\text { tham chiếu) }\end{array}$ \\
\hline $\begin{array}{c}\text { Phòng trọ } \\
\text { ơ ngoài }\end{array}$ & 69,4 & 30,6 & $0,98(0,66-1,44)$ \\
\hline $\begin{array}{c}\text { Ơ cùng gia } \\
\text { đình }\end{array}$ & 57,4 & 42,6 & $0,58(0,36-0,95) *$ \\
\hline
\end{tabular}

Nhận xét: Mức độ hài lòng chung về chất lượng dịch vụ giáo dục ở nhóm sinh viên nữ gấp 1,4 lần so với nhóm sinh viên nam (CI: 1,02 1,93). Nhóm sinh viên dân tộc Kinh có kết quả hài lòng chung về chất lượng dịch vụ giáo dục thấp hơn 2,27 lân so với nhóm sinh viên các dân tộc khác (CI: 1,04-4,97). Kết quả hài lòng chung ở khối Y6 thấp hơn khối Y4 0,61 lần (CI: 0,42 0,89 ). Về nơi ở hiên tại, nhóm sinh viên ở cùng gia đình có mức đổ hài lòng chung về chất lượng dịch vụ giáo dục bằng 0,58 lần so với nhóm sinh viên ở Ký túc xá Đại học Y Hà Nội (CI: 0,36 $0,95)$, sự khác biệt có ý nghĩa thống kê $(p<0,05)$.

\section{BÀN LUÂNN}

4.1. Thực trạng hài lòng vê dịch vụ giáo dục của sinh viên trường Đại học $Y$ Hà Nội

Tỷ lệ hài lòng chung (TLHLC) của sinh viên ở yếu tố tiếp cận dịch vụ giáo dục đạt $66,0 \%$. Điểm hài lòng chung (ĐHLC) của yếu tố tiếp cận dịch vụ giáo dục đạt $3,7 \pm 0,6$. So sánh $Đ H L C$ với kết quả khảo sát mức độ hài lòng của người học đối với dịch vụ giáo dục công của một số trường: Trường Đai học Bách khoa Đà Nẵng năm 2019 đạt 3,73 điểm [5]; Trường Đại học Ngoại thương năm 2020 đạt 3,975 điểm [6]; Trường Đại học Công nghiệp Hà Nội năm 2020 đạt 4,05 điểm[7]. Như vậy, kết quả khảo sát của Nhà trường có ĐHLC về yếu tố tiếp cận dịch vụ giáo dục tương đối thấp so với các trường so sánh. Tỉ lệ này cũng tương đối thấp so với kết quả khảo sát của Trường Đại học Kỹ thuật $Y$ tế Hải Dương $(57,4 \%)[4]$ và Trường Đại học Bách Khoa Đà Nẵng $(31,2 \%)[5]$.

Tỉ lệ hài lòng của sinh viên với yếu tố cơ sở vật chẩt của Nhà trường là $63,3 \%$. ĐHLC yếu tố cở sở vật chất của Nhà trường đạt $3,7 \pm 0,7$. So sánh ĐHLC với các khảo sát mức độ hài lòng của người học đối với dịch vụ giáo dục công của một số trường khác: Trường Đại học Bách khoa Đà Nẵng năm 2019 đạt 3,43 điểm [5]; Trường đại học Ngoại thương năm 2020 đạt 3,515 điểm [6]; Trường Đại học Công nghiệp Hà Nội năm 2020 đạt 4,09 [7]. Như vậy, kết quả khảo sát của Nhà trường nằm ở mức giữa với các trường so sánh.

Tỉ lệ hài lòng của sinh viên với yếu tố môi trường đào tạo đạt $72,7 \%$. ĐHLC 3,8 $\pm 0,7$. Kết quả này tương đồng Đại học Kỹ thuật $\mathrm{Y}$ tế Hải Dương (3,84 điểm), Đại học Bách khoa Đà Nẵng $(3,79$ điểm) [4],[5]; thấp hơn Trường đại học Ngoại thương (4,04 điểm), Đại học Công nghiệp Hà Nội $(4,03$ điểm) [6], [7].

Tỉ lệ hài lòng của sinh viên đối với yếu tố hoạt động đào tạo đạt $66,1 \%$. ĐHLC đạt 3,7 $\pm 0,7$. Kết quả này tương đồng Trường Đại học Kỹ thuật $Y$ tế Hải Dương (3,77 điểm) [4], cao hơn Trường Đại học Bách khoa Đà Nắng năm 2019 đạt 3,6 điểm [5] và thấp hơn Trường đại học Ngoại thương (3,94 điểm), Trường Đại học Công nghiệp Hà Nội (4,14 điểm) [6], [7]. Như vậy, kết quả khảo sát của Nhà trường nằm ở mức giữa với các trường so sánh.

Tỉ lệ hài lòng của sinh viên đối với yếu tố kết quả đào tạo đạt 54,9\%. ĐHLC đạt 3,5 $\pm 0,7$. Kết quả này thấp hơn Đại học $K y ̃$ thuật $Y$ tế Hải Dương ( 3,84 điểm), Đại học Bách khoa Đà Nẵng (3,71 điểm), đại học Ngoại thương (3,88 điểm), Đại học Công nghiệp Hà Nội (4,1 điểm) $[4],[5],[6],[7]$.

Tỉ lệ hài lòng chung về chất lượng dịch vụ giáo dục của Nhà trường đạt $67,4 \%$. Kết quả này thấp hơn Đại học Kỹ thuật $Y$ tế Hải Dương (71,3\%), Đại học Ngoại thương (76,9\%) [4],[6] nhưng cao hơn Trường Đại học Bách khoa Đà Nẵng $(57,1 \%)$ [5]. Như vậy, tỉ lệ hài lòng chung của Nhà trường nằm ở mức giữa so với các trường so sánh. Kết quả này cho thấy chất lượng dịch vụ giáo dục tại trường Đại học $Y$ Hà Nội đã đáp ứng được đa số sinh viên tham gia khảo sát.

4.2. Một số yếu tố liên quan đến sự hài lòng về dịch vụ giáo dục của sinh viên trường Đại học Y Hà Nội. Phân tích hồi quy logistic đa biến cho thấy có 4 yếu tố liên quan đến mức độ hài lòng chung của sinh viên với chất lượng dịch vụ giáo dục, bao gồm: giới tính, dân tộc, năm học, và nơi ở hiện tại của sinh viên.

Nghiên cứu có số sinh viên nữ tham gia khảo sát là $480 \mathrm{em}$, trong đó có $70,4 \%$ em có phản hồi hài lòng với chất lượng dịch vụ giáo dục của Nhà trường. Kết quả này cao hơn so với nhóm sinh viên nam tham gia khảo sát $(62,9 \%$ em hài lòng trên tổng 232 sinh viên nam tham gia nghiên cứu). Mức độ hài lòng chung của nhóm sinh viên nữ cao gấp 1,4 lần nhóm sinh viên nam $(p<0,05 ; C I: 1,02-1,93)$. Trên thực tế, sinh viên nam hoặc nữ đều được hưởng dịch vụ giáo dục tương tự nhau từ Nhà trường. Vì vậy, mặc dù mối liên quan giữa giới tính và mức độ hài 
lòng của sinh viên với dịch vụ giáo dục có ý nghĩa thống kê, nhưng chúng ta khó có thể tìm ra điểm khác biệt về dịch vụ giáo dục mà 2 đối tượng này tiếp cận. Kết quả này có thể do yếu tố cảm nhận chủ quan và sự khác biệt về tâm lý giữa hai giới nam và nữ.

Tham gia nghiên cứu có 668 sinh viên dân tộc Kinh và 44 sinh viên dân tộc khác, bao gồm Mường, Nùng, Tày, và một số dân tộc thiểu số khác. Mô hình hồi quy logistic đa biến cho thấy mức độ hài lòng của sinh viên ở nhóm dân tộc khác cao gấp 2,27 lần nhóm sinh viên dân tộc Kinh $(p<0,05 ; C I: 1,04-4,97)$. Ở câu hỏi sâu về các yếu tố của dịch vụ giáo dục, chỉ có 2 sinh viên trên tổng 44 sinh viên thuộc nhóm dân tộc khác phản hồi đề xuất cải thiện chất lượng cho Nhà trường, trong khi đó nhóm sinh viên dân tộc Kinh có rất nhiều đề xuất cải thiện cho từng yểu tố giáo dục. Kết quả này có thể do nhóm sinh viên dân tộc Kinh có khả năng được tiếp cận chất lượng giáo dục tốt hơn các dân tộc thiểu số ngay từ những cấp học trước đại học, vì vậy mà có góc nhìn tổng quát hơn, nhận định được các điểm cần cải thiện hơn ở dịch vụ giáo dục của Nhà trường. Vậy, Nhà trường cần cải thiện chất lượng giáo dục nói chung và cải tiến khả năng tiếp cận giáo dục tới các sinh viên dân tộc khác nói riềng, từ đó nâng cao mức độ hài lòng ở cả hai nhóm sinh viên dân tộc Kinh và các dân tộc khác.

Về yếu tố năm học, nghiên cứu khảo sát trên 3 nhóm đối tượng bao gồm các sinh viên hệ Bác sĩ thuộc khối Y4, Y5, và Y6. Mức độ hài lòng chung của nhóm sinh viên này thấp nhất và thấp hơn nhóm Y4 0,61 lần ( $p<0,05 ; C I: 0,42-0,89)$. Với nội dung đào tạo đa dạng, các sinh viên hệ bác sĩ từ năm thứ 4 đến năm thứ 6 đã trải nghiệm hầu như hoàn thiện các khía cạnh giáo dục của Nhà trường từ lý thuyết cho đến thực hành, trong đó, khối $Y 6$ là nhóm sinh viên tiếp cận đầy đủ nhất các dịch vụ giáo dục của Nhà trường. Ở câu hỏi sâu, nhóm sinh viên $Y 6$ đưa ra nhiều đề xuất cải thiện về cả 5 yếu tố nghiên cứu. Vì vậy, để nâng cao mức độ hài lòng ở nhóm sinh viên khối Y6, Nhà trường cần xem hê thống tiếp nhận và xử lí ý kiến của sinh viên là phương pháp quan trọng để kịp thời giải quyết hiệu quả, cải thiện các yếu tố giáo dục mà sinh viển cần, từ đó cải thiện chất lượng dịch vụ giáo dục. Ngoài ra, kết quả này có thể là tiền đề cho nghiên cứu tiếp theo nhằm tìm ra yếu tố trong đào tạo tác động trực tiếp đến sự hài lòng của nhóm sinh viên khối Y 6 trường Đại học Y Hà Nội.

Về yếu tố nơi ở hiện tại của sinh viên, nhóm sinh viên ở cùng gia đình có mức độ hài lòng chung thấp hơn 0,58 lần so với nhóm sinh viên ở Ký túc xá Đại học Y Hà Nội $(p<0,05 ; C I: 0,36$ $0,95)$. Ở câu hỏi sâu, nhóm sinh viên ở cùng gia đình đưa ra nhiều đề xuất về yếu tố cơ sở vật chất, đồng thời mức độ hài lòng của nhóm sinh viên này về cơ sở vật chất cũng thấp hơn nhóm ở ký túc xá. Vậy có thể thấy, cần tìm ra các yếu tố về cơ sở vật chất tác động đến mức độ hài lòng của nhóm sinh viên ở cùng gia đình, từ đó nâng cao mức độ hài lòng chung của nhóm này với dịch vụ giáo dục của Nhà trường.

Từ kết quả nghiên cứu, chúng tôi nhận thấy không có mối liên quan giữa các chuyên ngành với kết quả hài lòng về chất lượng dịch vụ giáo dục của sinh viên. Có thể nói, chương trình đào tạo và dịch vụ giáo dục ở các chuyên ngành Bác sĩ tuy khác nhau, nhưng đều thỏa mãn được nhu cầu học tập của sinh viên. TLHLC ở các khoa tương đối đồng đều với nhau và với TLHLC của toàn bộ sinh viên tham gia khảo sát $(67,4 \%)$, trong đó, nhóm Bác sĩ Đa khoa đạt tỉ lệ cao nhất (67,9\%), nhóm Bác sĩ Y học Dự phòng đạt tỉ lệ thấp nhất $(65,8 \%)$.

Như vậy, mức độ hài lòng chung của sinh viên về chất lượng dịch vụ giáo dục của trường Đại học Y Hà Nội có liên quan đến các yếu tố về giới tính, dân tộc, năm học, và nơi ở hiện tại.

\section{KẾT LUẦN}

1. Mức độ hài lòng của sinh viên hệ bác sĩ khối Y4 đến Y6 về chất lượng dịch vụ giáo dục trường Đại học Y Hà Nội năm học 2020 -2021 đạt $67,2 \%$.

2. Sự hài lòng các yếu tố nghiên cứu theo thứ tự từ cao xuống thấp: yếu tố môi trường đào tạo (tî̉ lệ hài lòng chung: $72,7 \%$ ); hoạt động đào tạo (tỉ lệ hài lòng chung: 66,1\%); tiếp cận dịch vụ giáo dục (tî lệ hài lòng chung: 66,0\%); cơ sở vật chất (tỉ lệ hài lòng chung: 63,6\%); kết quả đào tạo (tî lệ hài lòng chung: 54,9\%).

3. Có mối liên quan giữa các yếu tố giới tính, dân tộc, năm học, và nơi ở hiện tại của sinh viên với chất lượng dịch vụ giáo dục. Sự hài lòng về 2 yễu tố tiếp cận dịch vụ và môi trường đào tạo còn chịu tác động của năm học và chuyển ngành. Nơi ở hiện tại của sinh viển có mối liên quan với sự hài lò̀ng về yếu tố cơ sở vật chất.

\section{TÀI LIẸU THAM KHẢO}

1. Parasuraman AP, Zeithaml $V$, Berry $L$. SERVQUAL: A multiple- Item Scale for measuring consumer perceptions of service quality. Journal of retailing. Published online January $1,1988$.

2. Quyết đinh 2007/QĐ-BGDĐT 2019 Đo lường hài lòng đối với dịch vụ giáo dục công 20162020. Accessed November 19, 2020. 
https://thuvienphapluat.vn/van-ban/giaoduc/Quyet-dinh-2007-QD-BGDDT-2019-Do-luonghai-long-doi-voi-dich-vu-giao-duc-cong-2016-2020418928.aspx

3. Quyết đinh 2329/QĐ-BGDĐT 2017 tài liêuu Hướng dẩn đo lường hài lòng dịch vụ giáo dục công. Accessed November 19, 2020. https://thuvienphapluat.vn/van-ban/bo-may-hanhchinh/Quyet-dinh-2329-QD-BGDDT-2017-tai-lieuHuong-dan-do-luong-hai-long-dich-vu-giao-duccong-355737.aspx

4. Nguyê̂n TTH. Khảo sát sự hài lòng của người học về chất lượng dịch vụ giáo dục tại trường Đai học Kỹ thuật Y tế Hải Dương năm 20̉20: Báo cáo kết quả đề tài nghiên cứu khoa học cấp cơ sở ĐỀ TÀI NGHIÊN CƯUU KHOA HOC CẤP CƠ SỞ. ĐHKTYTHD; 2020. Accessed November 30, 2020. http:// 125.212.201.8:6008/handle/DHKTYTHD_123/6218

5.2020_2_27_1_9_131_1_-_dhbk_baocao-hailong -dvcong-2019-final.pdf. Accessed May 11, 2021.http://tvts.udn.vn/files/2020/2020_2_27_1_9 131_1_-_dhbk_baocao-hailong-dvcong-2019final.pdf

6. CLDVGDC.pdf. Accessed May 11, 2021. http://www.ftu.edu.vn/images/file/CLDVGDC.pdf

7. uffile-upload-no-title29679.pdf. Accessed May 11,2021. https://www.haui.edu.vn/media/29/uffileupload-no-title29679.pdf

\section{KIẾN THỨC VỀ STRESS CỦA SINH VIÊN NĂM THỨ 3 NGÀNH BÁC SỸ Y KHOA, TRƯỜNG ĐẠI HỌC Y HÀ NộI}

\section{TÓM TẮT}

Đặt vấn đề: Sinh viên y khoa là một trong những đối tượng có tỷ lê bi stress rất cao do áp lực của môi trường học tập. Việc hiểu biết đúng về stress giúp các em biết cách điêuu chỉnh và giải tỏa cũng như phòng ngừa hiệu quả. Mục tiêu: Mô tả kiến thức về stress của sinh viên năm thứ 3 ngành Bác sỹ Y khoa, Trường Đại học $Y$ Hà Nội. Đối tượng và phương pháp nghiên cứu: Nghiên cứu mô tả cắt ngang được thực hiên trên sinh viên năm thứ 3 ngành Bác sỹ Y khoa Trường Đại học $Y$ Hà Nội, bằng bộ câu hỏi gồm 2 phần: Thông tin chung và Kiến thức của sinh viên về stress. Kết quả: phần lớn sinh viên đã có kiến thức đúng về biểu hiên, nguyên nhân, ảnh hưởng và các cách ứng phó với stress. Tuy nhiên, vẫn còn có một tỷ lệ sinh viên không biết hoặc hiểu sai khi cho rẳng: Buồn chán, suy nghĩ tiêu cực và có ý định tự sát $(63,2 \%)$ là những biểu hiện khi bi stress; bị stress là do Tiếp xúc với người bị stress $(47,5 \%)$, do Số phận của mối người $(27,7 \%)$; Stress dẫn đến bi tâm thần, điên $(58,9 \%)$, Sử dụng thuốc an thần $(29,0 \%)$ khi bị stress. Kết luâan: Sinh viên đã có kiến thức đúng nhưng chưa đầy đủ về stress và còn có một số nhâm lẫn. Việc cung cấp đầy đủ, chính xác các kiến thức cơ bản về stress là hết sức cần thiết nhằm nâng cao hiểu biết của các em về vấn đề này.

Từ khóa: Kiến thức, stress; sinh viên y khoa

\section{SUMMARY}

KNOWLEDGE ABOUT STRESS OF THE THIRD YEAR MEDICAL DOCTOR STUDENTS, HANOI MEDICAL UNIVERSITY

Background: Medical students are one of the subjects with a very high rate of stress due to the

${ }^{1}$ Đai họ Y Hà Nội

Chịu trách nhiệm chính: Nguyễn Thị Thu Thủy

Email: nguyenthithuthuy@hmu.edu.vn

Ngày nhận bài: 18.8.2021

Ngày phản biên khoa hoc: 14.10.2021

Ngày duyệt bài: 21.10.2021

\section{Nguyễn Thị Thu Thủy ${ }^{1}$, Lê Thị Vũ Huyền ${ }^{1}$}

pressure of the learning environment. The proper understanding of stress helps you know how to adjust, reduce as well as prevent it effectively. Objectives: To describe the knowledge of stress of 3rd year students majoring in Medical Doctor, Hanoi Medical University. Subjects and methods: A cross-sectional descriptive study was carried out on 3rd year students majoring in Medical Doctor, Hanoi Medical University, by a questionnaire consisting of 2 parts: General information and Students' knowledge about stress. Results: The majority of students had accurate knowledge about the manifestations, causes, effects, and ways of coping with stress. However, there are students who do not know or misunderstand, which results in the facts that: Boredom, negative thoughts and suicidal intentions (63.2\%) are manifestations of stress; stress is caused by the Contact with stressed people $(47.5 \%)$; by the Fate of each person $(27.7 \%)$; Stress leads to psychosis, madness $(58.9 \%)$; Use tranquilizers $(29 \%)$ when stressed. Conclusion: students have correct but incomplete knowledge of stress some confusion. Adequate and accurate provision of basic knowledge about stress is essential in order to improve their understanding of this issue.

Keywords: Knowledge, stress, medical student

\section{I. ĐĂT VẤN ĐỀ}

Stress (căng thẳng) là một trong những "vấn đề" của con người ở mọi thời đại và tác động tới mọi mặt của đời sống. Stress xảy ra ở mọi lứa tuổi, mọi ngành nghề, đặc biệt là ở những người trẻ tuổi như tầng lớp thanh niên, sinh viên.

Sinh viên các trường y dược cũng là một trong những đối tượng đang phải chịu tác động mạnh mẽ của "căn bệnh này" khi phải sống và học tập trong môi trường đầy áp lực. Nghiên cứu của Trần Kim Trang về "Stress, lo âu và trầm cảm ở sinh viên y khoa" tại Đại học $Y$ Dược TP.Hồ Chí Minh chỉ ra: tỉ lệ sinh viên bị stress là 71,4\%[1]. Nghiên cứu của RC Harris, 